\title{
The effects of continuous administration of penicillin to successive generations of chicks
}

\author{
By M. E. COATES ANd M. K. DAVIES \\ National Institute for Research in Dairying, Shinfield, Reading \\ (Received 28 September 1958-Revised 2 Fanuary 1959)
}

For some years antibiotics have been included in the feed of young pigs and poultry to produce faster growth. With this widespread use, it is important to know whether there are any cumulative effects either on the mature treated animals or on successive generations of their progeny. The experiment here described was designed primarily to investigate whether the inclusion of penicillin in the diet of birds throughout life affected the early growth rate and the response to penicillin of their progeny. In addition, records of egg production, hatchability and mortality were kept and are presented, although these observations must be interpreted with caution in view of the small numbers involved. The mean annual response to penicillin of chicks from a commercial source is given for the last 5 years.

\section{EXPERIMENTAL}

\section{Design of experiment}

In 1955 the parental generation was formed from one hatch of about 200 unsexed chicks taken from a single flock of Light Sussex hens. It was divided into two groups of which one was given procaine penicillin continuously in the diet and the other had the same diet without the drug. The response to penicillin was measured by the percentage increase in weight at 4 weeks of the birds receiving the antibiotic over that of the corresponding controls. The pullet chicks were maintained on the two treatments throughout life, and for the next three generations hatches from each flock were tested in the same way for response to penicillin. In each successive generation sufficient pullet chicks from each of the two groups were treated in the same way as their dams and reared to maturity to give breeding flocks of about thirty-five to fifty hens.

The diagram below presents the design of the experiment.

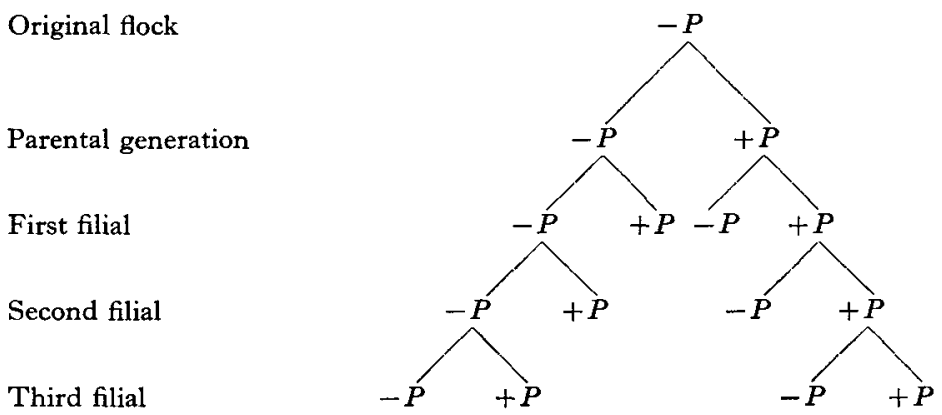




\section{Management}

Housing. The housing was as follows:

0-4 weeks of age: electrically heated tiered brooders as described by Coates, Kon \& Shepheard (1950)

4-8 weeks: unheated, carry-on tiered brooders

8-10 weeks approx.: movable fold units on grass

I I weeks onward: wooden poultry houses with grass runs

The control flock was kept as far as reasonably possible from exposure to penicillin either as dust from food or droppings from the penicillin flock.

Table I. Percentage composition of the diets

\begin{tabular}{|c|c|c|c|}
\hline Constituent & $\begin{array}{l}\text { Chick } \\
\text { mash }\end{array}$ & $\begin{array}{l}\text { Grower's } \\
\text { mash }\end{array}$ & $\begin{array}{c}\text { Breeder's } \\
\text { mash* }\end{array}$ \\
\hline Maize & 35 & I5.5 & Io \\
\hline Wheat & 30 & 16 & I 5 \\
\hline Barley & - & 20 & 14 \\
\hline Oats & 一 & 20 & 14 \\
\hline Miller's offals & $8 \cdot 5$ & 9 & 20 \\
\hline Dried grass & 3 & 5 & 5 \\
\hline Dried skim milk & $7 \cdot 5$ & - & - \\
\hline Fish meal & 10 & 3 & 10 \\
\hline Dried yeast & 3 & 3 & $2 \cdot 5$ \\
\hline Decorticated groundnut meal & $\ldots$ & 5 & 5 \\
\hline Bone meal & $\ldots$ & 0.83 & I \\
\hline Limestone & $\mathrm{I} \cdot 5$ & $1 \cdot 25$ & 2 \\
\hline Salts & $0.5 \dagger$ & $0.42 t$ & $0.5 t$ \\
\hline Vitamins $\mathrm{A}$ and $\mathrm{D}_{3}$ supplement & $1 \S$ & $\mathbf{1}$ & $I \|$ \\
\hline
\end{tabular}

Procaine penicillin was added at the rate of $45.5 \mathrm{~g} /$ ton chick mash and $10 \mathrm{~g} /$ ton grower's or breeder's mash.

* Contains I $\mathrm{mg}$ riboflavin/lb as I $\mathrm{lb} /$ ton Distafeed Riboflavin Supplement (Distillers Company (Biochemicals) Ltd).

$\dagger$ Percentage composition: $\mathrm{NaCl}_{93} \cdot 94, \mathrm{KI} 0 \cdot 06, \mathrm{MnSO}_{4} \cdot 4 \mathrm{H}_{2} \mathrm{O} 6$.

f Percentage composition: $\mathrm{NaCl}_{95}, \mathrm{MnSO}_{4} \cdot 4 \mathrm{H}_{2} \mathrm{O}_{5}$.

$\S$ Arachis oil containing 64 i.u. vitamin $\mathrm{D}_{3}$ and 680 i.u. vitamin $\mathrm{A} / \mathrm{g}$.

|| Nuclo, a proprietary meal containing in stabilized form 200 i.u. vitamin $D_{3}$ and 800 i.u. vitamin A/g (Cooper, McDougall and Robertson, Berkhampstead).

Diets. The basal diets were designed to be plentiful in all known nutrients and to support excellent growth. Their percentage composition is given in Table I. Chick mash was given from 0 to 8 weeks, grower's mash from 8 weeks to maturity and breeder's mash thereafter. Procaine penicillin was added to the appropriate diets at the rate of $45.5 \mathrm{~g} /$ ton chick mash and $10 \mathrm{~g} /$ ton breeder's and grower's mash. The level of penicillin in the chick diet was higher than is customary commercially, but is used as a routine in this laboratory in order to allow for possible losses during storage.

Mating. Mature Light Sussex cockerels were obtained from commercial breeders, a different source being used each year. Two or three cockerels ran with each flock, and were fed on breeder's mash with penicillin for $1_{4}$ days before they were placed with the hens.

Incubator practice. Eggs were collected over $\mathrm{I}_{4}$ days and set in a Papworth 2000-egg incubator. An unselected sample of from 90 to $25^{\circ}$ eggs from each flock was set. 
Eggs were candled after I8 days' incubation and infertile eggs removed from the incubator. All unhatched eggs remaining on the 22nd day were broken open, and the numbers of fertile eggs were corrected as a result of this examination. The hatchability was calculated as the percentage of fertile eggs hatched.

Records. Egg records were kept for each flock from beginning of laying. The length of time the birds were kept depended on the housing requirements at the time, so that the egg records were collected over varying times for each generation. All deaths occurring during the experiment were recorded and post-mortem examinations of birds over 8 weeks old were kindly made by Dr R. F. Gordon of Houghton Poultry Research Station.

\section{Measurement of chick response}

For testing, the chicks were brought into the laboratory at I day old. The progeny from each flock was divided into two, one half was given the diet with penicillin and the other the diet without. Test groups, occasionally duplicated, contained up to forty birds.

The percentage increase in weight of 4 -week-old chicks receiving penicillin over that of those not receiving penicillin was taken to represent the penicillin effect. Chicks do not always show an increase in growth with penicillin, particularly in newly cleaned premises (Coates, Dickinson, Harrison, Kon, Porter, Cummins \& Cuthbertson, 1952). In order to ensure an environment in which growth response to antibiotics might be expected, the tests were made when the chick rooms were full, and had been so for some time. The response of commercially bred chicks (Rhode Island Red $\times$ Light Sussex) from the A.R.C. Field Station, Compton, provided a standard with which chicks from the penicillin and control flocks, tested concurrently, could be compared. To coincide with full chick rooms, pullet-bred chicks from the experimental flocks had sometimes to be used, and their growth rate was less than that of the commercial chicks.

\section{RESULTS}

\section{Response of chicks}

The weights of chicks fed on the control and penicillin diets, from both experimental flocks and from the commercial source, are given in Table 2. There was no consistent difference in mean response to penicillin of chicks from the control and penicillin flocks in any generation, although the response varied from hatch to hatch and with the time of year.

In all but one hatch the commercial chicks on test at the same times showed a marked growth response to penicillin, indicating that the environment was suitable to reveal any differences in the effect of the antibiotic on the two experimental flocks. Averaged on both diets, the mean weight of the chicks from the penicillin flock was greater than that of chicks from the control flock, but this difference did not increase through the generations. The mortality of chicks from both experimental flocks was about $2 \%$, the same as that of commercial chicks.

During the last 5 years we have frequently tested penicillin on chicks from our commercial supply; the results of these tests are given in Table 3 . The mean weights 
of chicks given diets both with and without penicillin have not altered during this time. The environment remained one in which a positive response to penicillin of about ro $\%$ occurred.

Table 3. Effect of penicillin on body-weight of commercial chicks (seasonal means)

\begin{tabular}{|c|c|c|c|c|}
\hline \multirow[b]{2}{*}{ Season } & \multicolumn{4}{|c|}{ Mean weight at 4 weeks of age (g) } \\
\hline & $\begin{array}{c}\text { No. of } \\
\text { hatches† }\end{array}$ & Control & Penicillin & $\begin{array}{c}\text { Increase } \\
(\%)\end{array}$ \\
\hline r952-3 & 14 & 288 & 321 & $\mathrm{II} \cdot \mathrm{I} * * *$ \\
\hline $1953-4$ & 20 & 277 & 312 & $12 \cdot 6 * * *$ \\
\hline $1954-5$ & 22 & 292 & 323 & $10 \cdot 6 * * *$ \\
\hline $1955^{-6}$ & 20 & 294 & 328 & I I 6 6**** \\
\hline $1956-7$ & I 8 & 293 & 317 & $8 \cdot 2^{* * * *}$ \\
\hline
\end{tabular}

*** Significant at $P<0.00$ I by the $t$ test.

$\uparrow$ Experimental groups consisted of from twelve to forty chicks from each hatch.
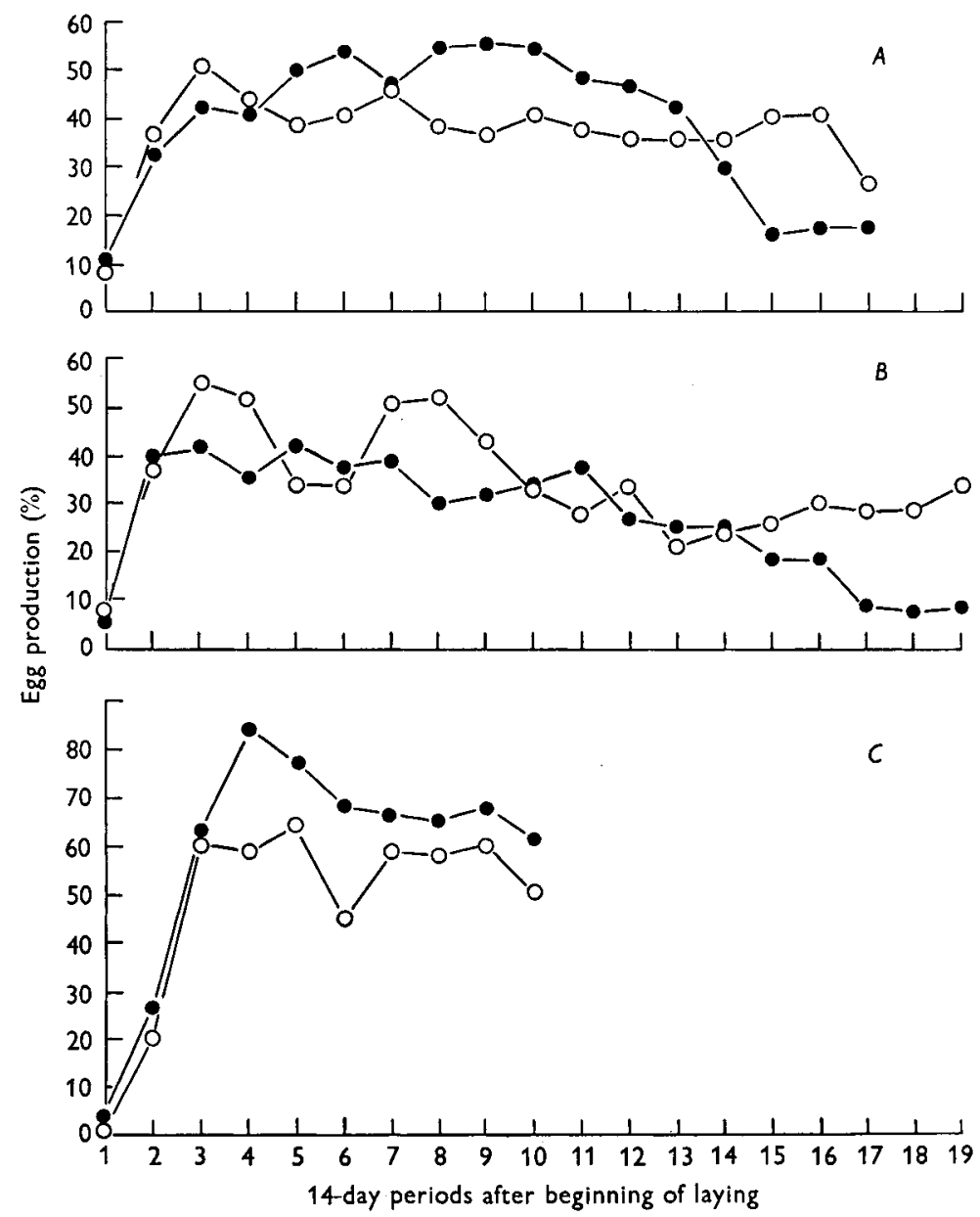

Fig. I. Percentage egg production of flocks of hens with and without penicillin. $A$, 1955, first filial generation; $B$, 1956, second filial generation; $C$, 1957, third filial generation; $\longrightarrow$, birds given penicillin; $\mathrm{O}-\mathrm{O}$, control birds. There were thirty-five to fifty hens in a flock at the beginning (see p. 205) but the numbers diminished throughout the season as birds died. 


\section{Other records}

Records of egg production, hatchability and mortality of the two breeding flocks were made as a routine, although as only two small flocks, not subjected to normal commercial culling, were concerned they are only of limited value. The percentage egg production of the survivors of the two flocks is shown in Fig. I. In the first and third filial generations the penicillin flock matured earlier and had higher production over the first 5 months than the control flock. This early advantage was offset by a relatively greater fall in production later. The hatchability of fertile eggs (Table 4 ) was slightly better in the penicillin-treated flock. This effect was not cumulative through the generations.

Table 4. Effect on hatchability of fertile eggs of penicillin given to hens through three generations

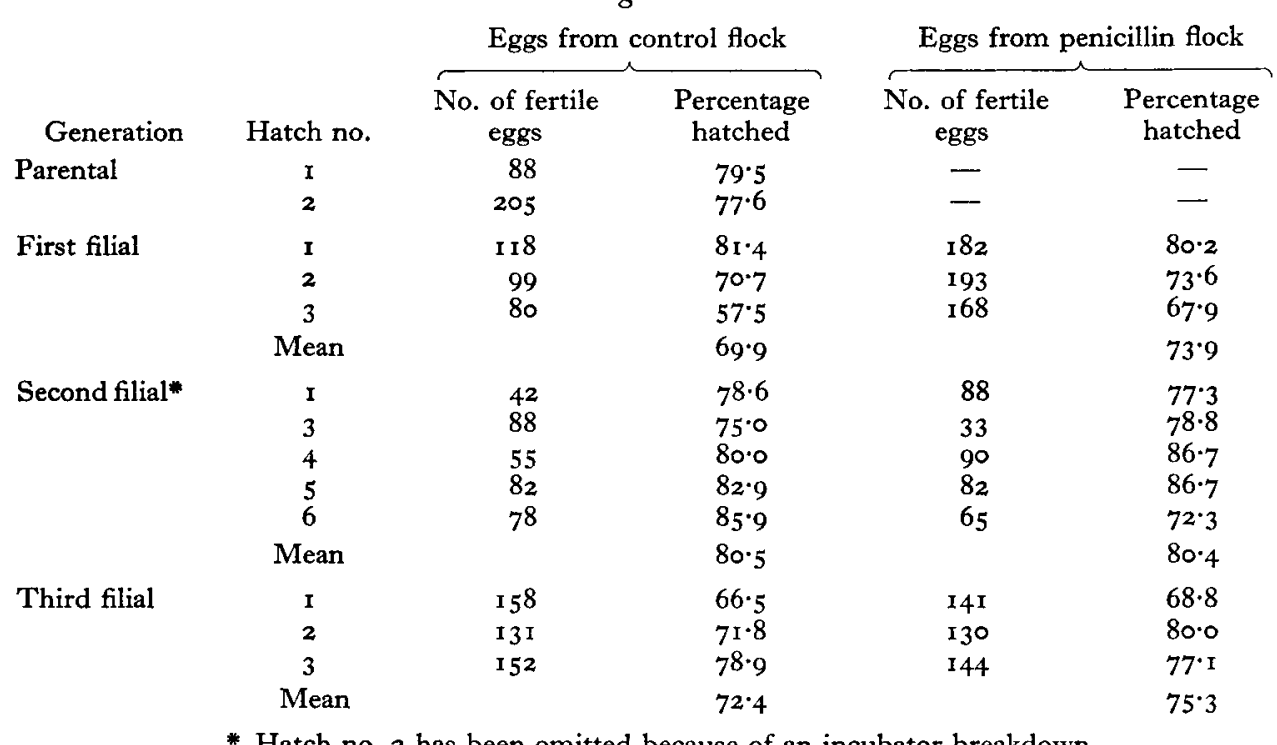

* Hatch no. 2 has been omitted because of an incubator breakdown.

After 4 weeks the control flock had a higher mortality than the penicillin flock, but the difference was only significant in the second filial generation when nine of fiftyeight birds in the penicillin flock and eighteen of fifty-six in the control flock died. The causes of death included fowl paralysis and nephritis and their distribution was the same in both flocks.

\section{DISCUSSION}

The increasing use of antibiotics in animal feeding has aroused considerable controversy regarding the possible long-term effects of this practice. Fears have been expressed that the widespread distribution of small quantities of antibiotics may encourage development of resistant strains of organisms, including pathogens, so that antibiotics may become ineffective not only as growth promoters but as therapeutic 
agents against certain diseases. The work of Smith \& Crabb (1957), who found predominantly tetracycline-resistant Escherichia coli in the faeces of pigs that had received diets containing low levels of tetracyclines lends support to this possibility; nevertheless, it is reasonable to expect that in animals given an antibiotic in the diet the surviving flora of the gut must be resistant to it. Conversely, Libby \& Shaible (1955) have claimed beneficial effects of the long-term use of antibiotics in poultry management. Their results suggest that when antibiotics are given for long periods in one place there is a change in the environmental flora allowing, by the suppression of detrimental organisms, better growth even in chicks not receiving the antibiotic in the diet. Hanson, Hill \& Ferrin (1956) collected data over 5 years on live-weight gains of different groups of pigs given penicillin or chlortetracycline. Their results showed no evidence of a trend in response to the antibiotics but rather that the magnitude of effect of antibiotic feeding depended on the state of health of the control animals at any time.

In our own chick rooms, dietary supplements of procaine penicillin, and occasionally other antibiotics including the tetracycline derivatives, have been in continuous use for several years. The rooms are emptied, disinfected and fumigated once each year but at all other times are well filled with chicks from day-old to 4 weeks of age. As Table 3 shows, there has been no tendency for the growth rate of control chicks not receiving antibiotics to change and the response to penicillin has remained of the order of $10 \%$. Although the rate of supplementation, $45.5 \mathrm{~g}$ procaine penicillin ( $\equiv 25 \mathrm{~g}$ penicillin)/ton diet, is higher than usual in practical poultry husbandry it is still very much below the 'therapeutic' level.

The experiments described here were undertaken to ascertain whether there was any cumulative effect of penicillin from generation to generation. In the three generations studied there was no indication that continuous administration of penicillin from hatching to maturity affected the ability of the next generation to respond to penicillin. No detrimental effects of antibiotic supplementation were observed; in fact, the weights of chicks from the flock given penicillin were on the whole slightly greater, and the mortality less, than those of chicks from the control flock. Similarly, egg production and hatchability were in general slightly better in the flock receiving penicillin. These apparent improvements may have been a real effect of the antibiotic supplement, but it is possible that they arose as a result of chance selection even though the original two flocks were taken at random from a single population. In any event these benefits remained slight and did not increase from one generation to the next. Our experience is very similar to that of Jennings (1957) who also found no adverse effect of penicillin on breeding performance of hens and slight apparent advantages in egg production, hatchability and body-weight of their chicks. However, he also regarded these findings with reserve since they could have arisen from chance genetic variations, especially as in one of the generations large chicks from the penicillin flock were traced to one particular sire.

It is clearly unjustified to draw too close a parallel between comparatively small trials in the laboratory and the broader aspects of practical poultry husbandry. Only years of experience in the field will determine the wisdom of using antibiotics in 
animal feeding. However, within the limits of the experiments reported here we have found no evidence of a detrimental effect of the continuous use of antibiotics. There were even indications of benefit, apart from the stimulation of early growth rate, although the slight improvements in performance were not cumulative through successive generations.

\section{SUMMARY}

I. Two flocks of Light Sussex hens were maintained for three generations, one with and the other without the addition of procaine penicillin to the diets. The growth response to penicillin of successive generations of their progeny was measured, and some records of egg production, hatchability and mortality were kept.

2. There was no evidence of any detrimental effects of the antibiotic but some indications of a lower mortality and a slight improvement in the performance of mature hens given penicillin and in the weight of their progeny. These effects, however, were not cumulative throughout the three successive generations.

3. Results for the past 5 years are presented for the growth response to penicillin of commercially bred chicks reared to 4 weeks of age in this laboratory. No change was observed in the magnitude of effect of the antibiotic or in the absolute weights of the birds.

We are grateful to Dr S. K. Kon for his helpful interest in this work and to Mr F. E. Rogers, N.D.P.H., and Miss E. J. Phillips for the care and management of the flock.

\section{REFERENCES}

Coates, M. E., Dickinson, C. D., Harrison, G. F., Kon, S. K., Porter, J. W. G., Cummins, S. H. \& Cuthbertson, W. F. J. (1952). F. Sci. Fd Agric. 3, 43 .

Coates, M. E., Kon, S. K. \& Shepheard, E. E. (1950). Brit. F. Nutr. 4, 203.

Hanson, L. E., Hill, E. G. \& Ferrin, E. F. (1956). F. Anim. Sci. 15, 280.

Jennings, R. C. (1957). World's Poult. Sci. $\mathcal{F} .13,284$.

Libby, D. A. \& Shaible, P. J. (1955). Science, r21, 733.

Smith, H. W. \& Crabb, W. E. (I957). Vet. Rec. 69, 24. 